The Indigenous Data Landscape in Canada: An Overview

Jeanette Steffler

Director, Strategic Research, Indigenous and Northern Affairs Canada

aboriginal policy studies Vol. 5, no. 2, 2016, pp. 149-164

This article can be found at:

http://ejournals.library.ualberta.ca/index.php/aps/article/view/26992

ISSN: 1923-3299

Article DOI: http://dx.doi.org/10.5663/aps.v5i2.26992

aboriginal policy studies is an online, peer-reviewed and multidisciplinary journal that publishes original, scholarly, and policy-relevant research on issues relevant to Métis, non-status Indians and urban Aboriginal people in Canada. For more information, please contact us at apsjournal@ualberta.ca or visit our website at www.nativestudies.ualberta.ca/research/aboriginal-policy-studies-aps. 


\section{The Indigenous Data Landscape in Canada: An Overview ${ }^{1}$}

Jeanette Steffler

Director, Strategic Research, Indigenous and Northern Affairs Canada

\section{Indigenous Data in High Demand}

Quality information is necessary for governments to put in place solid policies and programs effectively, to demonstrate accountability, and to be transparent to their citizens. Such information is the foundation upon which evidence-based decisions are made and monitored. Outside of government, academics and private businesses also depend on information to gain knowledge of what does and does not work, to conduct scientific and socioeconomic research, and to support advancements in a rapidly evolving communication environment. Quality information is undeniably a key component to improving sustainable development and addressing well-being gaps.

All forms of information are important in helping to shape the policy narrative - from quantitative analysis, including descriptive statistics and causational analysis, to more qualitative social, cultural, legal and historical research underlying present circumstances, this information helps to answer that fundamental question of how we got here. Acknowledging this means acknowledging that quantitative data can be extremely powerful. Data are among the simplest ways to benchmark present status, demonstrate need, and measure progress over time.

The need for quality data to help effect improvements in socioeconomic outcomes is particularly relevant for First Nation, Métis, and Inuit people in Canada. Recent research shows that while most basic socioeconomic indicators for the Indigenous population in Canada are improving, gaps between Indigenous and non-Indigenous populations continue to persist. For example, Indigenous peoples, particularly First Nations and Inuit, have some of the lowest educational outcomes in the country, which constitute a challenging barrier to increased well-being and participation in the economy. ${ }^{2}$ At the same time, the Indigenous population is very young and growing rapidly. The potential to leverage this growing and youthful population, particularly as Canada enters a period of labour supply shortages, represents a significant opportunity for the future health and prosperity of Indigenous communities and for the Canadian economy and society as a whole.

The need for targeted data, research, and policy development is further compounded by the vast diversity of Indigenous peoples, with distinct cultures and languages, who reside in various urban, rural, and sometimes very remote locations. The geographic realities alone

1 The views expressed in this report are those of the author and not those of the Government of Canada.

2 According to the 2011 National Household Survey, just under half of Registered Indians living on reserve and Inuit aged twenty-five to sixty-four have no certificate, diploma or degree (46.6 percent and 48.5 percent, respectively), compared to 11.8 percent of other Canadians. About 73 percent of Inuit live in one of the Inuit Land Settlement Regions - Nunatsiavut, Nunavik, Inuvialuit, and Nunavut.

aboriginal policy studies, vol. 5, no. 2, 2016

www.nativestudies.ualberta.ca/research/aboriginal-policy-studies-aps

ISSN: $1923-3299$ 
can present varied barriers and opportunities that depend on access to services and jobs as well as fundamental needs such as access to land, potable water, and sustainable food.

Addressing well-being gaps is a high priority for Indigenous communities, peoples, and governments at all levels. Targeted research, particularly in the areas of health, education, and employment, is critical. At the same time, research must be integrated with cultural and traditional knowledge, such as Indigenous languages and history, so that the policy narrative is framed in a meaningful and relevant way.

Action needed to address Indigenous research and data gaps is further underscored by several recommendations arising from the Truth and Reconciliation Commission of Canada (2015). ${ }^{3}$ Many of its recommendations have important implications from a data collection, sharing, and analysis perspective. It explicitly references the need for research and policy development, monitoring, evaluation, and annual reporting to Parliament and the people of Canada on post-apology progress. Specifically, the recommendations call for monitoring progress on closing the gaps between Indigenous and non-Indigenous communities on a number of health and socioeconomic indicators such as infant mortality, maternal health, suicide, chronic diseases, education, and income.

Globally, the United Nations General Assembly recently adopted the "Transforming our World: The 2030 Agenda for Sustainable Development," which comes with 17 Sustainable Development Goals (SDGs) that articulate global action to eradicate poverty and set a forward-looking path to a sustainable and prosperous planet and resilient peoples. ${ }^{4}$ The declaration includes a pledge to leave no one behind, with explicit references to Indigenous peoples. Defining success and measuring progress at the global, national and regional levels are important aspects of the implementation of the 2030 SDGs. A key challenge, however, is the collection of data that can be disaggregated to ensure that goals stay true to the original intent and plan of action. The SDGs also acknowledge that baseline data for several of the SDG targets is unavailable, and much work needs to be done to ensure "increased support for strengthening data collection and capacity-building in Member States, to develop national and global baselines, where they do not yet exist."

In the context of world Indigenous peoples, there is a general lack of disaggregated data. Preliminary analysis from the National Institute of Demographic and Economic Analysis in New Zealand showed that about fifty-five percent of countries do not count Indigenous peoples in their national population censuses (2005-2014 decennial census round). While this has improved somewhat over time (the same statistic was sixty-six percent during the 1985-1994 decennial census period), insufficient identification of Indigenous respondents remains a significant barrier for many countries in terms of their ability to assess gaps and monitor Indigenous well-being. By contrast, the CANZUS countries (Canada, Australia, New Zealand, and the United States) have multiple Indigenous data identifiers, which can

3 Truth and Reconciliation Commission of Canada: Calls to Action. http://www.trc.ca/websites/trcinstitution/ File/2015/Findings/Calls_to_Action_English2.pdf.

4 United Nations. Transforming our world: The 2030 Agenda for Sustainable Development. https://sustainabledevelopment.un.org/post2015/transformingourworld. 
be disaggregated by ethnicity, language and geography. ${ }^{5}$ In general, the CANZUS countries are leading the pack when it comes to data on Indigenous populations. ${ }^{6}$

Despite Canada's relatively strong international leadership in terms of Indigenous data availability, significant data collection challenges remain domestically. While a great deal of data exists for the non-Indigenous population, most of these sources either do not have Indigenous identifiers or do not have sufficient Indigenous representation in the sampling methodology to produce reliable disaggregated estimates. For example, producing estimates for many socioeconomic indicators at the sub-national level for the Indigenous population living in urban areas or in small communities can be challenging due to the relatively small number of Indigenous peoples living in these settings. In addition, the majority of data sources targeting the general Canadian population do not necessarily collect data that Indigenous peoples would consider to be culturally relevant. Consequently, many data sources fall short in terms of providing a better understanding of the underlying contextual factors that could directly or indirectly influence Indigenous health and socioeconomic outcomes.

While data collection can be costly, the scarcity of quality Indigenous information is due in part to the way in which Indigenous research has been conducted as well as issues surrounding the governance of Indigenous information. Typically, large-scale research and survey programs were conducted with little input from Indigenous communities and peoples. This approach has created a situation in which there is a lack of trust, "buy in," and participation on the part of Indigenous communities - inevitably affecting the overall quality of the data.

The concern regarding Indigenous jurisdiction over data collection processes in Canada was articulated in volume 3 of the Report of the Royal Commission on Aboriginal Peoples in 1997:

The gathering of information and its subsequent use are inherently political. In the past, Aboriginal people have not been consulted about what information should be collected, who should gather that information, who should maintain it, and who should have access to it. The information gathered may or may not have been relevant to the questions, priorities and concerns of Aboriginal peoples. Because data gathering has frequently been impacted by outside authorities, it has met with resistance in many quarters. (RCAP 1997, 4)

Today, Indigenous communities and organizations are seeking more autonomy and are moving towards self-government. They are also gaining greater control over their

5 National Institute of Demographic and Economic Analysis, University of Waikato, New Zealand, unpublished data from "Ethnicity Counts?". http://www.waikato.ac.nz/nidea/research/ethnicitycounts.

6 However, as pointed out by John Taylor and Tahu Kukutai in an unpublished report titled "Indigenous Data Sovereignty and Indicators: Reflections from Australia and Aotearoa New Zealand," while the CANZUS countries do have comprehensive data collection systems on Indigenous populations, many of these systems do not necessarily meet Indigenous principles or needs for "data sovereignty." 
information and the overall Indigenous research agenda. With a common goal among researchers and Indigenous communities to produce research that makes a difference, a partnership-based approach is becoming a necessary prerequisite to any Indigenous data collection and research program. Furthermore, a partnership-based approach ensures a mutual understanding of research objectives, practices, protocols and that ethical research guidelines and criteria are put in place.

\section{Indigenous Data Landscape in Canada - An Overview}

In Canada, there are three major sources of data for the Indigenous population that cover demographic and socioeconomic concepts for a variety of geographic locations:

- Administrative data

- Census of population and the National Household Survey

- Special Surveys

These data sources are briefly summarized in Table 1 and described below.

\section{Administrative Data}

Administrative data are important for program reporting, compliance and accountability requirements. In general, however, administrative data or systems do not often collect data on program outcomes or consequences. Rather, they tend to be "output-based" and designed to keep track of "units delivered/serviced." In addition, administrative data tend to lack the kind of metadata (e.g., data dictionaries and methodological frameworks), standard demographic data fields, and Indigenous identifiers, which can present limitations in terms of their utility for Indigenous policy research.

A good example of an administrative database is the Indian Register maintained and managed by Indigenous and Northern Affairs Canada since 1951. The Indian Register contains the authoritative list of individuals registered with the federal government as Indians, according to the terms of the Indian Act. The Indian Register contains the names of individuals, dates of birth and death, and marital status, as well as residency information. Accessible only under strict privacy rules and conditions, the Indian Register can be a valuable source of information from which to produce basic demographic statistics, such as population counts and fertility and mortality statistics for Registered Indians in Canada. However, the Register does not include information on socioeconomic circumstances, such as employment status, educational attainment, income, or housing. Because this data source is narrowly defined, its usefulness for research purposes is thus limited.

Nevertheless, administrative data sets can have great potential for use in the research domain. As information technologies evolve and become more efficient, methods to link and associate different administrative databases are becoming increasingly effective and cost-efficient. Through data linkage, it is possible to assess outcomes and results, especially if the data are longitudinal and individuals can be followed over their lives' course. In the context of making a contribution to the Indigenous Data Landscape, administrative data sets could be and should be further explored and developed. 
TABLE 1: Indigenous Data Landscape - Major Sources of Data in 2015

\begin{tabular}{|c|c|c|c|c|c|}
\hline & Data Instrument & Description/Scope & Delivery & Delivery & Population \\
\hline $\begin{array}{l}\frac{\pi}{\pi} \\
\frac{0}{\varepsilon} \\
\frac{5}{0}\end{array}$ & $\begin{array}{l}\text { Administrative } \\
\text { Data }\end{array}$ & $\begin{array}{l}\text { Information that is collected for } \\
\text { operational and/or legislative } \\
\text { requirements or reporting } \\
\text { requirements under the terms } \\
\text { and conditions of funding } \\
\text { agreements. Output-oriented } \\
\text { data that focus on "units" } \\
\text { instead of outcomes. }\end{array}$ & $\begin{array}{l}\text { Federal } \\
\text { government } \\
\text { provinces, } \\
\text { territories, } \\
\text { municipalities }\end{array}$ & \multicolumn{2}{|c|}{$\begin{array}{l}\text { Various geographies and } \\
\text { populations (including } \\
\text { populations living on reserve } \\
\text { lands), depending on the } \\
\text { administrative database. }\end{array}$} \\
\hline 号 & $\begin{array}{l}\text { Census of } \\
\text { Population* }\end{array}$ & $\begin{array}{l}\text { Collects basic demographic } \\
\text { information on individuals } \\
\text { including residence, age, } \\
\text { gender, family structure and } \\
\text { language. } \\
\text { (*Includes } 2011 \text { National } \\
\text { Household Survey - voluntary } \\
\text { survey instrument attached to } \\
\text { the } 2011 \text { Census Cycle) }\end{array}$ & $\begin{array}{l}\text { Statistics } \\
\text { Canada }\end{array}$ & \multicolumn{2}{|c|}{$\begin{array}{l}\text { All Canadians, provinces and } \\
\text { territories, including the } \\
\text { Aboriginal population living } \\
\text { on- and off-reserve. } \\
\text { Aboriginal Identify data since } \\
1986 \text { (First Nations } \\
\text { Registered/ Non-Registered, } \\
\text { Métis and Inuit) }\end{array}$} \\
\hline \multirow{5}{*}{ 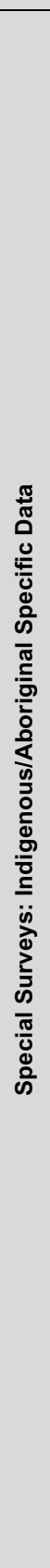 } & $\begin{array}{l}\text { Aboriginal Peoples } \\
\text { Survey (Post- } \\
\text { Censal Survey) }\end{array}$ & $\begin{array}{l}\text { 1991,2001, } 2006 \text { Aboriginal } \\
\text { Peoples Survey - Omnibus } \\
\text { survey of socioeconomic } \\
\text { characteristics of Aboriginal } \\
\text { children and adults } \\
2012 \text { Aboriginal Peoples } \\
\text { Survey on Education and } \\
\text { Employment - In } 2012 \text { the } \\
\text { survey design was changed } \\
\text { from an omnibus format to a } \\
\text { thematic format, focusing on } \\
\text { high-priority topics. } \\
\text { 2017 Aboriginal Peoples } \\
\text { Survey on Aboriginal } \\
\text { Participation in the } \\
\text { Economy - Currently under } \\
\text { development }\end{array}$ & $\begin{array}{l}\text { Statistics } \\
\text { Canada }\end{array}$ & $\begin{array}{l}\text { Off-reserve, } \\
\text { north and } \\
\text { urban } \\
\text { ( }{ }^{\star} \text { for } 1991 \\
\text { and } 2001, \\
\text { on-reserve } \\
\text { data is } \\
\text { available in } \\
\text { selected } \\
\text { regions) }\end{array}$ & $\begin{array}{l}\text { First Nations } \\
\text { living off- } \\
\text { reserve, } \\
\text { Métis, } \\
\text { Inuit }\end{array}$ \\
\hline & $\begin{array}{l}\text { Thematic } \\
\text { Socioeconomic } \\
\text { Surveys in First } \\
\text { Nation } \\
\text { Communities }\end{array}$ & $\begin{array}{l}\text { First Nations Regional Early } \\
\text { Childhood, Education and } \\
\text { Employment Survey } \\
\text { (2013/2014) } \\
\text { First Nations Regional } \\
\text { Employment and Labour } \\
\text { Survey (2017/2019)- } \\
\text { Currently under development }\end{array}$ & $\begin{array}{l}\text { First Nations } \\
\text { Information } \\
\text { Governance } \\
\text { Centre }\end{array}$ & $\begin{array}{l}\text { On-reserve } \\
\text { and in } \\
\text { northern First } \\
\text { Nation } \\
\text { communities }\end{array}$ & First Nations \\
\hline & $\begin{array}{l}\text { Regional Health } \\
\text { Survey (RHS) and } \\
\text { Community Survey }\end{array}$ & $\begin{array}{l}\text { National health survey } \\
\text { covering wellness topics and } \\
\text { determinants of health. Piloted } \\
\text { in } 1997 \text { it was first conducted } \\
\text { in } 2002 / 03 \text {. Most recent cycle } \\
\text { was } 2008 / 2010 \text {. Next cycle } \\
2015 / 2017 \text {. }\end{array}$ & $\begin{array}{l}\text { First Nations } \\
\text { Information } \\
\text { Governance } \\
\text { Centre }\end{array}$ & $\begin{array}{l}\text { On-reserve } \\
\text { and in } \\
\text { northern First } \\
\text { Nation } \\
\text { communities }\end{array}$ & First Nations \\
\hline & $\begin{array}{l}\text { Programme for the } \\
\text { International } \\
\text { Assessment of } \\
\text { Adult } \\
\text { Competencies }\end{array}$ & $\begin{array}{l}2012 \text { OECD-led survey } \\
\text { measuring the level and } \\
\text { distribution of skills among the } \\
\text { adult population as well as the } \\
\text { utilization of skills in different } \\
\text { contexts. }\end{array}$ & $\begin{array}{l}\text { Statistics } \\
\text { Canada }\end{array}$ & $\begin{array}{l}\text { Conducted in } \\
24 \text { countries. } \\
\text { Canadian } \\
\text { sample } \\
\text { included } \\
\text { Aboriginal } \\
\text { and non- } \\
\text { Aboriginal } \\
\text { populations } \\
\text { living off- } \\
\text { reserve. } \\
\text { National } \\
\text { estimates } \\
\text { available and } \\
\text { in selected } \\
\text { provinces. }\end{array}$ & $\begin{array}{l}\text { First Nations } \\
\text { living off- } \\
\text { reserve, } \\
\text { Métis, } \\
\text { Inuit }\end{array}$ \\
\hline & $\begin{array}{l}2006 \text { Aboriginal } \\
\text { Children's Survey } \\
\text { (ACS) }\end{array}$ & $\begin{array}{l}\text { One time Post-censal survey } \\
\text { of early Aboriginal childhood } \\
\text { development (0-5 years) }\end{array}$ & $\begin{array}{l}\text { Statistics } \\
\text { Canada }\end{array}$ & $\begin{array}{l}\text { Off-reserve, } \\
\text { north and } \\
\text { urban }\end{array}$ & $\begin{array}{l}\text { First Nations } \\
\text { living off- } \\
\text { reserve, } \\
\text { Métis, } \\
\text { Inuit }\end{array}$ \\
\hline
\end{tabular}


An additional and important consideration in the development of administrative data is the governance of Indigenous information. This is important because of the increasing demand of Indigenous communities to control the collection and use of information pertaining to them. Most administrative data sets are governed and controlled by governments, with little or no engagement with Indigenous communities. At the same time, reporting requirements under the terms and conditions of financial transfers can be onerous for the communities to complete and of little research or policy value.

\section{The Census of Population}

The Census of Population, including the voluntary 2011 National Household Survey, is a very important source of data. Conducted by Statistics Canada, it provides high-level, comparable national demographic and socioeconomic information for all Canadians, including Indigenous peoples. Census data are available for specific Indigenous populations (Registered Indians, Non-Status Indians, Métis and Inuit). Aboriginal identity ${ }^{7}$ and registration status information is collected through self-identification. ${ }^{8}$

The power of the census is that it collects data on universal concepts that are designed to provide a breadth of information on all Canadians. As the census uses an omnibus design - meaning that it collects high-level information in every cycle on a wide variety of topics for a variety of users - it allows for continuity and trend analysis. It also uses standard geographical concepts (e.g., Census Subdivisions, Census Metropolitan Areas, etc.) that enable analyses of the relationships between socioeconomic factors such as education and geo-spatial factors such as proximity to services and resource development. The census is especially useful in uncovering gaps experienced across Indigenous populations (First Nation, Métis and Inuit) as well as in comparison to non-Indigenous populations.

The Community Well-Being (CWB) Index is a good example of how the Census of Population is used to produce a key policy-research tool. The CWB produces well-being scores for First Nation, Inuit, and other Canadian communities across Canada, and is composed of four basic dimensions: education, income, employment, and housing. It is a basic way of assessing the socioeconomic gap between Indigenous and non-Indigenous communities. It is not a perfect measure of well-being, as it does not take into account such important aspects of well-being as health, culture, and language. It does, however, provide strong evidence of persistent well-being gaps between Indigenous communities and nonindigenous communities over time (it offers a 30-year time series). ${ }^{9}$

7 The term "Aboriginal" is commonly used in Canada as a way to refer to all Indigenous peoples in Canada. The term has a legal context, stemming from the Canadian Constitution Act, 1982, Section 34, which states that "Aboriginal peoples of Canada' includes the Indian, Inuit and Métis peoples of Canada." This term is used interchangeably throughout this commentary to indicate First Nations, Inuit, and Métis people.

8 Definitions of Aboriginal peoples can be complicated. Aboriginal identity and self-identification can be variable over time and are not necessarily transferred from one generation to the next, which can result in very different population statistics and characteristics over time. Guimond, Robitaille, and Senécal provide an overview of these definitions in "Aboriginal Peoples of Canada: A Population with Many Definitions," $221-51$.

9 More information on the community well-being index is available at http://www.aadnc-aandc.gc.ca/eng/1 $100100016579 / 1100100016580$. 
There are other comparative census-based research products that are essential to understanding gaps and differences among populations. These research products cover numerous subject matter areas such as demographic projections, mobility/migration analysis, ethnic mobility, parenting patterns/outcomes, education attainment, and labourforce participation, housing needs, and gender disparity analysis. These examples show how census-based analyses contribute to measuring important gaps and demonstrating need. However, due to the omnibus nature of the census, the census data can only partially explain the underlying factors or determinants of socioeconomic outcomes. This is particularly true in the context of Indigenous peoples, who are very diverse and have cultures, histories, and circumstances that differ from community to community or nation to nation.

\section{Special Surveys: Indigenous-Specific Data}

In contrast to the Census of Population, targeted social surveys can offer a depth of information on more specific topics and for unique populations. They are usually voluntary and use sampling techniques to produce estimates that are representative of the target population for various levels of geography (e.g., sub-national geographies including provinces and territories).

Statistics Canada conducts a number of special surveys of the general Canadian population to obtain more detailed information on specific topics such as youth, the environment, health, and employment. However, few of these surveys have sampling approaches that produce national and regional estimates that are representative of all Indigenous peoples (First Nations, Métis and Inuit), most notably because they typically exclude residents of First Nations communities (i.e., on reserves). ${ }^{10}$ The resulting lack of disaggregated data on Indigenous populations creates a significant challenge for researchers.

This situation is offset to a great extent by a small number of nationally implemented surveys designed specifically for Indigenous populations, and developed with the aim of collecting in-depth data on high-priority topics of mutual interest and benefit. The value and contribution of these survey instruments to the Indigenous data landscape cannot be overemphasized. These special surveys aim to collect unique data on topics that matter to Indigenous peoples. Without high-quality, culturally-relevant data, it would be extremely challenging to produce research that would be effective in informing program and policy initiatives, especially if the research is meant to illuminate better the diverse challenges and opportunities faced by First Nation, Métis, and Inuit peoples.

Table 1 provides a summary of the major national-level survey instruments that are uniquely designed for Indigenous peoples in Canada or have significant Aboriginal representation in their samples and generally allow for disaggregation by Aboriginal group (First Nation, Métis, Inuit) for selected regions. It is important to note that the list is not exhaustive. For example, it does not include important survey instruments that are regionspecific or conducted at the sub-national level. In addition, it includes only individual and

10 The Labour Force Survey, conducted by Statistics Canada, is a good example of an important survey instrument that covers Indigenous populations at a very high level (national, some regions and off-reserve only). 
household-level surveys and does not include surveys that target larger units of analysis such as businesses, organizations, and communities.

These omissions notwithstanding, Table 1 represents a summary of special survey instruments that make a significant contribution to the Indigenous data landscape in Canada. Each provides valuable, targeted data that cover important health and socioeconomic topics and offer varying degrees of coverage with respect to Indigenous identity, age, geography, and place of residence.

Two of the survey programs listed are described in further detail below: (1) the Aboriginal Peoples Survey conducted by Statistics Canada; and (2) the health and thematic socioeconomic surveys conducted by the First Nations Information Governance Centre.

The Aboriginal Peoples Survey (APS)

The APS is an established, voluntary post-censal survey that has become an essential part of the Indigenous data landscape. Established in 1991, the APS was a major achievement in terms of providing a unique source of information on the Indigenous population in Canada, and has had particular success in the collection of data on First Nations living off reserve, Métis and Inuit. The 2001 APS was part of Canada's response to the Royal Commission on Aboriginal Peoples as outlined in Gathering Strength-Canada's Aboriginal Action Plan (1997). Furthermore, in 2001 the survey's concepts were developed closely with National Aboriginal Organizations. ${ }^{11}$

In 1991, 2001, and 2006 the APS used an omnibus approach much like the census. It was designed to complement the census by providing additional contextual information on health and socioeconomic topics. ${ }^{12}$ For the most part, the content of the APS remained the same between 1991 and 2006. However, as it lacked the level of detail needed to isolate determinants of high-priority outcomes, the survey was not used as extensively as expected, and ultimately made only a limited contribution to targeted policy research. This was also partially due to a general lack of capacity to conduct research on Indigenous issues. In addition, there were data-collection challenges due to a lack of participation by First Nation communities, which caused a data gap for First Nations living on reserve and in northern communities. $^{13}$

11 The Aboriginal Peoples Survey was developed and implemented in partnership with the following National Aboriginal Organizations: Congress of Aboriginal Peoples (CAP); Inuit Tapiriit Kanatami (ITK); Métis National Council (MNC); National Association of Friendship Centres (NAFC); Native Women's Association of Canada (NWAC).

12 Previous cycles of the APS collected a breadth of information on health topics and determinants of health. Basic information on employment, education, health, housing, and language was also collected.

13 The 1991 APS was the only cycle in which data were available for Aboriginal peoples in all regions, on- and off-reserve, and in the north. Even then, however, 195 communities did not participate or survey enumeration was interrupted. In 2001, national estimates were not available because there was no participation in the survey from First Nation communities in Quebec. In 2006, the APS was not conducted in First Nation communities. 
The 2012 APS introduced a thematic survey design to produce in-depth, unprecedented data in key policy areas. For the 2012 cycle, the theme was Aboriginal education and employment. Data concepts in the 2012 APS were targeted to address long-standing policy questions, such as "What are the characteristics of successful Indigenous students?", "What are the barriers and levers to employment?" and "What supports do Indigenous students require to ensure their success?"

In 2017, the APS will focus on Aboriginal participation in the economy, collecting data that will help inform policies and programs aimed at improving labour-market outcomes for Indigenous peoples. This survey will include concepts regarding factors that facilitate or prevent participation in the labour force, labour mobility, and post-secondary education attainment. For continuity purposes, the new thematic design of the APS will always include core indicators on socioeconomic topics not covered by the main theme, such as health, language, income, and housing. Another important development for the 2017 APS is that additional questions will be asked regarding Aboriginal identity for the Métis and Inuit populations in order to facilitate understanding about membership and affiliations with Indigenous organizations.

Since 1991, the capacity to conduct research on Indigenous issues has increased significantly in communities, governments, and academia. This, combined with the new thematic design of the APS and a growing urgency to find effective ways to improve Indigenous well-being, has generated an unprecedented demand to mine the APS to explore policy-research questions. For example, since the 2012 APS release (November 2013), Statistics Canada has received over a thousand data-table requests, and their initial overview report has been downloaded over 14,000 times and viewed over 34,000 times. ${ }^{14}$ Several research analyses and reports using the APS have already been published on government websites and academic journals, with more expected in the years to come.

\section{Health and Thematic Socioeconomic Surveys in First Nation Communities}

There are two major survey instruments conducted on-reserve and in northern First Nation communities: the First Nations Regional Health Survey (RHS), and the First Nations Early Childhood, Education and Employment Survey (FNREEES). Both are conducted by the First Nations Information Governance Centre. ${ }^{15}$ These surveys make a significant contribution to the Indigenous data landscape by collecting detailed information in First Nation communities that is not captured by any other data sources in Canada. More importantly, they are the only major survey instruments that use an in-depth process of engagement with national, regional, and community-level First Nation representatives and leaders.

Prior to these surveys, there was a substantial deficit of meaningful, culturally relevant data available on First Nation communities. The lack of data was partially explained by the very nature of how Indigenous policy research was conducted. Typically, research and survey programs were conducted in isolation, with little or no direct input from

14 Statistics Canada as of December 2015.

15 See http://fnigc.ca/. 
Indigenous communities and peoples. In the view of some Indigenous peoples, they had been "researched to death." ${ }^{16}$ Concerns regarding the privacy and protection of personal information are some of the other factors behind First Nation dissatisfaction with and distrust of federal government surveys.

In reaction to the way research and data collection was being conducted, a set of guiding principles referred to as $\mathrm{OCAP}^{\circledR}$ (Ownership, Control, Access and Possession) was introduced. ${ }^{17} \mathrm{OCAP}^{\oplus 18}$ refers to a set of guiding principles that assert First Nations' collective ownership and control over research and data collection and management activities in First Nation communities. ${ }^{19}$ These principles were the foundation upon which the RHS was built.

The RHS and the FNREEES are also conducted under strict privacy policies and protocols similar to other major national survey initiatives. They also follow cultural frameworks. ${ }^{20}$ A Harvard University review of the 2002-2003 RHS survey commended the First Nations Information Governance Centre for its success in providing quality information, and in particular for supporting governance of First Nation information. According to the review:

Compared to comparable surveys of Indigenous people from around the world, the 2002-2003 RHS was unique in its explicit incorporation of First Nations values into the research design and in the intensive collaborative engagement of First Nations people and their representatives at each stage of the research process. (Harvard Project 2006, iv)

The RHS is now currently in its third official phase (cycle). It collects data related to both Indigenous and non-Indigenous understandings of health and well-being, covering a broad range of health determinants such as oral health, injury and disability, chronic health conditions, traditional culture, and physical activity and nutrition. Since the introduction of the RHS over two decades ago, it has become recognized as a fundamental source of high-quality data on health in First Nations communities that influences and informs policy- and decision-making in a number of First Nation health programs.

Built on the success of the RHS, the FNREEES represents a major milestone in

$16 \mathrm{http} / / /$ fnigc.ca/sites/default/files/docs/ocap_path_to_fn_information_governance_en_final.pdf.

17 Introduced in 1998 by the National Steering Committee of the First Nations and Inuit Regional Longitudinal Health Survey.

$18 \mathrm{OCAP}^{\oplus}$ is a registered trademark of The First Nations Information Governance Centre that can only be used under license or used with permission.

$19 \mathrm{OCAP}^{\circledast}$ is fundamentally related to self-determination, the preservation and development of First Nations’ culture and an assertion of governance over First Nation information and research. Applying the First Nation principles of $\mathrm{OCAP}^{\oplus}$ to research and data collection means, in the view of First Nations, the ability to exercise the right to jurisdiction and governance within this domain. It is especially important for First Nation communities and leaders, as governance of information is fundamental for culturally respectful and meaningful decisionmaking, and critical to effective community planning, nation re-building, and reconciliation.

20 See, for example, http://fnigc.ca/sites/default/files/ENpdf/RHS_General/developing-a-cultural-framework.pdf. 
terms of filling a significant data gap on education and employment topics in First Nation communities. Conducted between 2013 and 2015, the First Nations Information Governance Centre just recently released preliminary statistics from the survey during a conference titled Now is the Time: Our Data, Our Stories, Our Future. The full report will be available in March 2016. The survey is expected to provide new data that will support various priority policy initiatives, including the implementation of recommendations from the Truth and Reconciliation Commission, early learning and childcare programming, promoting economic development, and creating jobs for Indigenous peoples.

A third survey instrument, currently under development by the First Nations Information Governance Centre, will be implemented between 2016/17 and 2020/21 and will cover employment and labour topics. ${ }^{21}$ This new survey will measure concepts similar to the 2017 APS, but for First Nations living on reserves and in northern First Nation communities. ${ }^{22}$ It will include topics such as participation in the labour force, labour mobility, and postsecondary educational attainment. In accordance with all surveys conducted by the First Nations Information Governance Centre, it will be implemented respecting the principles of $\mathrm{OCAP}^{\circledR}$ and an extensive engagement process with national, regional, and communitylevel First Nation representatives and leaders.

\section{Data Governance and Partnership-based Approaches}

Good Indigenous research needs good, meaningful data. In Canada, the Indigenous data landscape is steadily evolving, and its future is very promising. Not only do unique survey instruments exist for Indigenous peoples, but there a growing number of data sources are being developed by Indigenous peoples, for Indigenous peoples. These unique data sources, complemented by general sources such as the Census of Population, offer researchers and policymakers considerable opportunities to produce meaningful and important research that will make a positive difference to Indigenous health and well-being.

Notwithstanding important improvements to the Indigenous data landscape, data gaps are still a major challenge, especially in comparison to the data that exist for all Canadians and in cases in which disaggregation by Indigenous populations is not possible or meaningful at the sub-national level. Issues surrounding the governance of Indigenous information will also continue to be a key consideration in any Indigenous data advancements or developments.

$21 \mathrm{http} / / /$ fnigc.ca/news/new-survey-fill-long-standing-gap-first-nations-labour-and-employment-data.html.

22 The thematic socio-economic surveys and the Aboriginal Peoples Survey are a part of a broader survey program titled the "Surveys on Aboriginal Peoples". This survey program is supported by Indigenous and Northern Affairs Canada, in partnership with Health Canada and Employment and Social Development Canada. The objective of the survey program is to support the development of data that will help Indigenous communities and organizations, federal, provincial and territorial governments, as well as other interested parties make informed decisions on employment, education, health, language, income, housing and mobility for First Nation, Métis and Inuit populations living on- and off-reserve and in northern communities. http:// www.aadnc-aandc.gc.ca/eng/1321384019753/1322059098232\#aps. 
At its core, jurisdiction over data is a key aspect of good governance. It increases a community's capacity to make sound, evidence-based decisions and to be accountable for its actions by reporting to its members on progress. For Indigenous communities and peoples, data can be a strategic resource:

Data about citizens and community members is a strategic resource. Reliable data, carefully gathered an analyzed, can strengthen the ability of tribes to pursue their own goals. Armed with dependable and relevant information, tribes can be strategic, envisioning a role for data as part and parcel to sovereignty and governance. They can be responsive, initiative projects to address emerging needs. They can be culturally authoritative, asserting control over which topics are measured, and how. As tribes meaningfully engage with data, qualitative information about Native populations will enhance - rather than detract from the vibrancy and resiliency of tribal communities. (Schultz and Rainie 2014, 1)

Indigenous jurisdiction over data also implies that there has to be a dialogue and a mutual understanding of what research collaboration would mean to all partners and a will to explore ways to build and leverage Indigenous research capacity. To a large extent, meaningful collaboration is about respecting the aspirations of Indigenous communities their members and the process and protocols of data collection and research activities in those communities and of those individuals. For Indigenous communities, it is essentially about how the information will be defined, collected, developed, stored, and used. It is also about how the communities can build their own research capacity and be better-positioned to develop sustainable policy solutions. For users, the bottom line is about relevancy, access, and assurance that the research will bring about positive change. Relevancy can only be defined through collaboration, accountability, and mutual goals, whereas access is simply defined by protocols and process.

While governments, universities, and Indigenous communities recognize the need to build respectful and effective research relationships, more needs to be done in terms of establishing formal understandings of what true data and research collaboration means to Indigenous peoples. With a common goal of producing research that makes a positive difference, there is also a shared responsibility to ensure that the research is conducted ethically, in culturally appropriate ways, and is not used or interpreted in a manner that will cause harm or perpetuate discrimination and stereotypes.

The RHS and the FNREEES data initiatives are paving the way to establishing greater data governance and research capacity in First Nation communities and organizations. Other Indigenous data and research governance initiatives, such as the British Columbia 
First Nations Data Governance Initiative ${ }^{23}$ and the Urban Aboriginal Knowledge Network, ${ }^{24}$ are evolving and setting out similar governance and research collaboration processes to ensure that Indigenous communities have a greater stake. Another example is a reference to $\mathrm{OCAP}^{\circledast}$ in the Tri-council Policy Statement: Ethical Conduct for Research Involving Humans, which is a joint ethics statement issued by the Canadian Institutes for Health Research, Natural Sciences and Engineering Research Council, and Social Sciences and Humanities Research Council. ${ }^{25}$

These are but a few examples that show that data and research collaboration with Indigenous partners is becoming the new norm, and is a fundamental, necessary prerequisite to obtaining high-quality, robust information for all users. Ultimately, these Indigenous-led and innovative approaches are helping to "reset" the Indigenous data and research landscape, and represent an important step towards the greater goal of stronger nation-to-nation relationships, reconciliation, and improved well-being for Indigenous peoples across Canada.

23 The British Columbia First Nations Data Governance Initiative (BCFNGI) aims to strengthen public policy in British Columbia through Indigenous engagement and capacity building. It uses a community-driven, nation-based approach aimed at focusing on community accountability, building capacity, and strengthening governance. Its ultimate goal is to use data to support strategic investments in comprehensive health and wellness plans at the local, regional, and provincial levels. See http://www.bcfndgi.com.

24 The Urban Aboriginal Knowledge Network (UAKN) is a research network of urban Aboriginal communities, policymakers and academics engaging in policy-relevant and community-driven research with the goal of improving the well-being of urban Aboriginals across Canada. The UAKN governance brings together urban Aboriginal communities, academics, governments, and others stakeholders in pursuit of knowledge creation, mobilization and transfer. See http://uakn.org/.

25 The statement advocates the need to build trusting relationships that lead to research that is collaborative and of mutual benefit. The introduction of OCAP ${ }^{\circ}$ into the policy is an important step for the granting councils. The policy specifically states that "researchers should consult their own institutions to ensure that the application of $\mathrm{OCAP}^{\star}$ or other community-based ethics codes is consistent with institutional policies. Where divergences exist, they should be addressed and resolved prior to the commencement of the research" (118). 


\section{Bibliography}

Aboriginal Affairs and Northern Development Canada. 2014. The Community Well-Being (CWB) Index. Ottawa. Accessed November 30, 2015. http://www.aadnc-aandc. gc.ca/eng/1100100016579/1100100016580.

Aboriginal Affairs and Northern Development Canada. 2015. The Community Well-Being Index: Well-Being in First Nations Communities, 1981-2011. Ottawa. Accessed November 30, 2015. http://www.aadnc-aandc.gc.ca/eng/1345816651029/1345816 742083.

British Columbia First Nations Data Governance Initiative. 2016. Accessed November 30, 2015. http://www.bcfndgi.com/.

Bruhn, J. 2014. "Identifying Useful Approaches to the Governance of Indigenous Data." The International Indigenous Policy Journal 5(2). Accessed November 30, 2015. http:// ir.lib.uwo.ca/iipj/vol5/iss2/5. doi:10.18584/iipj.2014.5.2.5.

Canadian Institutes of Health Research, Natural Sciences and Engineering Research Council of Canada and Social Sciences and Humanities Research Council of Canada. 2010. Tri-Council Policy Statement: Ethical Conduct for Research Including Humans. Accessed November 30, 2015. http://www.pre.ethics.gc.ca/pdf/eng/tcps2/ TCPS_2_FINAL_Web.pdf.

First Nations Governance Centre (FNIGC). 2014a. Ownership, Control, Access and Possession (OCAPTM): The Path to First Nations Information Governance. Accessed November 30, 2015. http://fnigc.ca/sites/default/files/docs/ocap_path_to_fn_ information_governance_en_final.pdf.

First Nations Information Governance Centre. 2014b. "Barriers and Levers for the Implementation of OCAP ${ }^{\mathrm{m}}$." The International Indigenous Policy Journal 5(2): 1-18. http://ir.lib.uwo.ca/iipj/vol5/iss2/3. Accessed November 30, 2015. doi:10.18584/ iipj.2014.5.2.3.

Government of Canada Justice Laws Website. 2016. Constitution Act, 1982. Accessed November 30, 2015. http://laws-lois.justice.gc.ca/eng/Const/Index.html.

Guimond E., N. Robitaille, and S. Senécal. 2010. "Les Autochtones du Canada : une population aux multiples definitions - Aboriginal Peoples of Canada: A Population with Many Definitions." Cahiers québécois de démographie 38(2): 221-51. http:// www.erudit.org/revue/cqd/2009/v38/n2/044815ar.html?vue=resume.Accessed November 30, 2015. doi:10.7202/044815ar. 
Harvard Project on American Indian Economic Development. 2006. Review of the First Nations Regional Longitudinal Health Survey (RHS) 2002/2003. Accessed November 30, 2015.

http://fnigc.ca/sites/default/files/ENpdf/RHS_2002/rhs_harvard_independent_ review.pdf.

Indian Affairs and Northern Development Canada. 1997. Gathering Strength: Canada's Aboriginal Action Plan. Accessed November 30, 2015. http://www.ahf.ca/ downloads/gathering-strength.pdf.

Indigenous and Northern Affairs Canada. 2016. "Surveys on Aboriginal Peoples." Accessed November 30, 2015. https://www.aadnc-aandc.gc.ca/eng/1321384019753/132205 9098232.

International Work Group for Indigenous Affairs. 2015. Indigenous Peoples Major Group Position Paper on Proposed SDG Indicators. Accessed November 30, 2015. http:// www.iwgia.org/iwgia_files_publications_files/0724_SDG_Indicators_Final_ eb.pdf.

Royal Commission on Aboriginal Peoples (RACP). 1997. Report of the Royal Commission on Aboriginal Peoples. Volume 3: Gathering Strength. 4.

Schultz, J.L., and S.C. Rainie. 2014. “The Strategic Power of Data: A Key Aspect of Sovereignty." The International Indigenous Policy Journal 5(4): 1-5. http://ir.lib. uwo.ca/iipj/vol5/iss4/1. doi:10.18584/iipj.2014.5.4.1.

Statistics Canada. 2012. Aboriginal Peoples Survey. Accessed November 30, 2015. http://www23.statcan.gc.ca/imdb/p2SV. pl? Function=getSurvey $\&$ SDDS $=3250 \&$ lang $=e n \& d b=i m d b \& a d m=8 \& d i s=2$.

——_. 2016. "Labour Force Survey." Accessed November 30, 2015. http://www.statcan. gc.ca/eng/survey/household/3701.

- - - 2012. "Programme for the International Assessment of Adult Competencies." Accessed November 30, 2015. http://www23.statcan.gc.ca/imdb/p2SV. pl? Function=getSurvey\&SDDS $=4406$.

- - - 2011. "Census of Population and the National Household Survey." Accessed November 30, 2015. http://www12.statcan.gc.ca/census-recensement/index-eng. cfm. 
Taylor J., and T. Kukutai. 2015. "Indigenous Data Sovereignty and Indicators: Reflections from Australia and Aotearoa New Zealand.” Paper presented at the UNPFII Expert Group Meeting on The Way Forward: Indigenous Peoples and the 2030 Agenda for Sustainable Development, United Nations, New York, Oct 22-23.

Truth and Reconciliation Commission of Canada. 2015. Honouring the Truth, Reconciling for the Future: Summary of the Final Report of the Truth and Reconciliation Commission of Canada. Accessed November 30, 2015. http://nctr.ca/assets/reports/Final\%20Reports/Executive_Summary_English_Web. pdf.

Truth and Reconciliation Commission of Canada. 2012. Calls to Action. Accessed November 30, 2015. http://nctr.ca/assets/reports/Calls_to_Action_English2.pdf.

United Nations. 2015. Transforming our World: The 2030 Agenda for Sustainable Development. Sustainable Development Knowledge Platform. Accessed November 30, 2015. https://sustainabledevelopment.un.org/post2015/transformingourworld/ publication

Urban Aboriginal Knowledge Network. 2016. Accessed November 30, 2015. http://uakn. org/. 